\title{
Pancreatic Ductal Adenocarcinoma and Its Precursor Lesions
}

\section{Histopathology, Cytopathology, and Molecular Pathology}

\author{
Bing Ren, Xiaoying Liu, and Arief A. Suriawinata
}

From the Department of Pathology and Laboratory Medicine, Dartmouth-Hitchcock Medical Center, Lebanon, New Hampshire

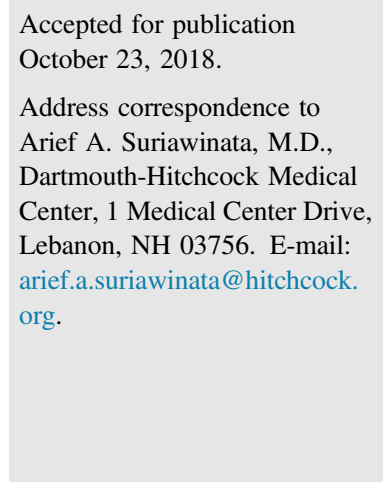

Accepted for publication

October 23, 2018

Lebanon, NH 03756. E-mail:

arief.a.suriawinata@hitchcock.

org.

Pancreatic ductal adenocarcinoma (PDAC) is the most common type of pancreatic cancer, comprising $90 \%$ of all malignant pancreatic neoplasms, with a dismal 5-year survival rate of $8 \% .^{1,2}$ In the United States, it is the fourth leading cause of cancer death in both males and females. In 2018, the estimated number of new pancreatic cancer cases in the United States is 55,440, and the estimated death caused by pancreatic cancer is 44,330. ${ }^{1}$ Its frequency has been increasing in the past several years, and it is predicted to be the second leading cause of cancer death by $2030 .^{2}$ Studies have suggested that it takes at least 10 years for a mutated pancreatic cell to develop into an invasive disease, which provides hope for early detection.

In the past decade, our knowledge on identification and characterization of pancreatic carcinoma and its precursor lesions has dramatically improved because of large-scale genome sequencing. Endoscopic ultrasound (EUS)-guided fine-needle aspiration (FNA) has become the adopted method in procuring tissue for PDAC diagnosis. In this article, we present a review of clinical and pathologic features, molecular alterations, prognosis, and management of PDAC and its precursor lesions. We discuss the recently introduced two-tier classification system of precursor lesions and updates in staging criteria based on the recently published eighth edition of the American Joint Committee on Cancer (AJCC) Cancer Staging Manual. ${ }^{3}$ Finally, we discuss the potential clinical applications based on molecular and genetic information for early detection.

Disclosures: None declared.

A.A.S. and Gregory Tsongalis are co-guest editors of the Pancreatic Cancer Theme Issue. A guest editor acted as the Associate Editor for this article. No one at Dartmouth-Hitchcock Medical Center was involved in the peer review process or final disposition.

This article is a part of a review series on benign and neoplastic pancreatic lesions from their pathologic to molecular profiles and diagnoses. 


\section{Precursor Lesions of Pancreatic Ductal Adenocarcinoma}

PDAC arises from noninvasive precursor lesions, which include a noncystic lesion [pancreatic intraepithelial neoplasia (PanIN)] and cystic lesions [intraductal papillary mucinous neoplasm (IPMN), intraductal tubulopapillary neoplasm (ITPN), and mucinous cystic neoplasm (MCN)]. PanINs are diagnosed microscopically in pancreatic resection or biopsy specimens, whereas cystic lesions are diagnosed clinically by radiological examinations.

Based on the 2010 World Health Organization classification, ${ }^{4}$ precursor lesions of PDAC (PanIN, IPMN, and $\mathrm{MCN}$ ) are divided into three grades of dysplasia-low, intermediate, and high grade. Clinical evidence shows that lesions with low- and intermediate-grade dysplasia have a low risk of malignant progression and are amenable to clinical observation, whereas lesions with high-grade dysplasia have a high risk of progression into invasive carcinoma and require surgical management. Therefore, a two-tier classification system - low and high grade-was proposed at an international consensus meeting to improve diagnostic concordance and to align histopathology with clinical practice. The former PanIN-2 and intermediategrade dysplasia are classified into low grade in the twotier system.

\section{Pancreatic Intraepithelial Neoplasia}

PanINs are histologically identified as microscopic mucinous pancreatic ductal lesions $(<0.5 \mathrm{~cm})$. Low-grade PanIN encompasses flat, papillary to micropapillary columnar mucinous epithelium with bland to atypical nuclei, nuclear stratification, crowding, and hyperchromasia (Figure 1A). High-grade PanIN encompasses flat to papillary, micropapillary, or cribriform formation with severe nuclear atypia, loss of polarity, macronucleoli, and abnormal mitotic figures (Figure 1B).

In a resection specimen, high-grade PanIN is sometimes difficult to distinguish from dilated neoplastic glands of PDAC. Furthermore, high-grade PanIN may represent intraductal spread of invasive carcinoma or cancerization of the ducts. Therefore, when high-grade PanIN is identified, adequate sampling and cautious histologic examination are crucial in excluding the presence of an invasive component. ${ }^{5}$

The progression of PanIN, along with IPMN and MCN, to PDAC is considered similar to stepwise carcinogenesis of colorectal carcinoma. In this process, the early events include telomere shortening, KRAS mutation, and $C D K N 2 A$ (p16) loss, whereas p53 and SMAD4 loss occurs in the late stage. Studies have shown that KRAS mutations, telomere shortening, and Her2 overexpression were detected in low-grade PanIN, whereas p16 and SMAD4 loss and TP53 and BRCA2 mutations were found in high-grade PanIN. ${ }^{4,6} \mathrm{~A}$ recent study of isolated high-grade PanIN (not associated with invasive PDAC) showed that KRAS and CDKN2A mutations were detected in the low-grade PanINs, whereas the TP53 mutation only occurred in a minor portion of highgrade PanINs and SMAD4 mutation was completely absent. ${ }^{7}$ A possible explanation of this finding is that many highgrade PanIN lesions in the earlier studies were intraductal spread of invasive cancer, or isolated high-grade PanIN might be biologically different from high-grade PanIN with associated PDAC.

\section{Intraductal Papillary Mucinous Neoplasm}

IPMN is defined as radiologically or grossly recognizable cystic neoplasms $(>1 \mathrm{~cm})$ arising in and communicating with the pancreatic ductal system. IPMNs are equally prevalent in men and women, and they are usually diagnosed at 60 to 70 years of age. ${ }^{8}$ The characteristic radiologic features of IPMNs are cystic lesions, involvement of pancreatic duct system, dilation of main and/or branch ducts, and atrophy of surrounding pancreatic parenchyma. ${ }^{9}$ The endoscopic finding of mucin extrusion from dilated ampulla of Vater is pathognomonic for IPMN. ${ }^{10}$ Based on the involvement of pancreatic ducts, IPMNs can be divided into three types: main duct, branch duct, and mixed types. Main-duct IPMN usually occurs in the head of the pancreas with a dilated main pancreatic duct. Branch-duct IPMN involves side branches of pancreatic duct. Mixed-type IPMN involves both main and branch ducts.

According to the morphology of mucinous epithelium, IPMNs are classified into four histologic subtypes: gastric, intestinal, pancreatobiliary, and oncocytic types (Figure 1, C-F). Gastric-type IPMN resembles gastric foveolar epithelium. Intestinal-type IPMN is similar to a colonic villous adenoma with goblet cells. Pancreatobiliary-type IPMN has cuboidal neoplastic lining cells with minimal mucin, enlarged nucleoli, and complex architecture. Oncocytic-type IPMN [alias intraductal oncocytic papillary neoplasm (IOPN)] typically presents with eosinophilic neoplastic cells and complex architecture, including arborizing papillae, solid nests, cribriform growth pattern, and intraepithelial lumina. Multiple histologic types can be found within an IPMN, and the dominant component determines its subtype. Approximately $25 \%$ of IPMNs do not have one dominant type of epithelium; instead, they are lined by a mixed type of epithelium. ${ }^{11}$

Different types of IPMNs have distinct mucin expression, which is helpful in determining their subtypes. Gastric-type IPMN expresses MUC5AC; the intestinal type expresses MUC2 (and CDX2); the pancreatobiliary type expresses MUC1 and sometimes focal MUC6; IOPN expresses MUC1 (in some cases), MUC6, and Heppar1 (and expression of Heppar1 is uncommon in other types of IPMNs). ${ }^{12}$

Based on the degree of dysplasia, IPMNs are classified into low and high grade. The morphologic changes of the spectrum of dysplasia in IPMN parallel those seen in 

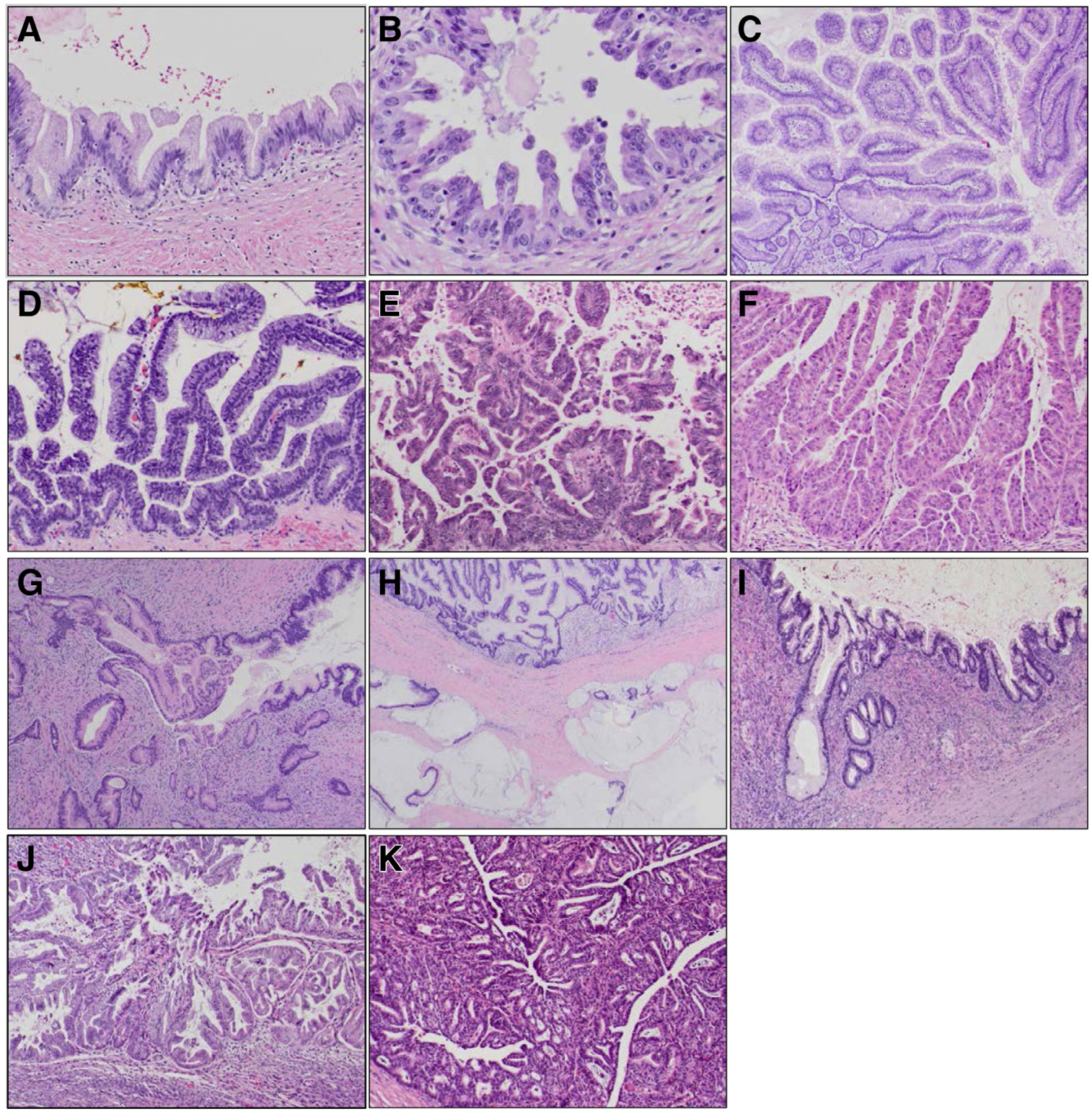

Figure 1 A and B: Pancreatic intraepithelial neoplasia: low grade (A) and high grade (B). C-F: Subtypes of intraductal papillary mucinous neoplasms (IPMNs): gastric (C), intestinal (D), pancreatobiliary (E), and oncocytic (F) types. G: Invasive tubular carcinoma arising in IPMN with infiltrating growth pattern and desmoplastic stroma. H: Invasive colloid carcinoma arising in IPMN with mucinous neoplastic epithelium floating in the extracellular mucin pools. I and J: Mucinous cystic neoplasm, low grade (I) and high grade (J), with ovarian-type stroma underlying the mucinous neoplastic epithelium. K: Intraductal tubulopapillary neoplasm with cribriform architecture, minimal mucin production, and high-grade dysplasia. Hematoxylin and eosin stain was used for all images. Original magnification, $\times 200(\mathbf{A}-\mathbf{K})$.

PanINs. The cytologic and architecture atypia increases as IPMN progresses from low to high grade. Compared with low-grade IPMN, high-grade IPMN shows complex architecture, irregular and hyperchromatic nuclei with loss of polarity, and stratification. Gastric-type IPMNs are usually low grade, intestinal type may be low or high grade, and pancreatobiliary IPMN and IOPN are frequently high grade. $^{5}$

Whole-genome sequencing of IPMNs revealed frequent $K R A S, G N A S$, and RNF43 mutations. A KRAS mutation was detected in most IPMNs (47\% to 81\%), even in small incipient IPMNs (defined as 0.5 to $1 \mathrm{~cm}$ ), which supports the hypothesis that KRAS is one of the most important driver genes during IPMN development. ${ }^{13,14}$ GNAS is the second most commonly mutated gene ( $41 \%$ to $66 \%$ ), and almost all intestinal-type IPMNs harbor a GNAS mutation. RNF43 is a potential tumor suppressor gene, a negative regulator of the Wnt signaling pathway, and frequently inactivated in IPMNs. ${ }^{15}$ Genetic alterations of TP53, CDKN2A, STK11, $B R A F, S H H$, and BRGI have also been reported in IPMNs. ${ }^{16}$ Inactivation of both TP53 and CDKN2A is associated with transformation of IPMN to invasive carcinoma. 
There is a correlation between the STK11 mutation and Peutz-Jegher syndrome. Gradual loss of BRGl expression correlates with increasing degree of dysplasia. Recently, telomere fusion was detected in high-grade IPMN or IPMN with associated invasive carcinoma, but not in normal-duct or low-grade IPMNs. ${ }^{17}$

Although IOPN was regarded as an oncocytic variant of IPMN in the World Health Organization 2010 classification, there is growing evidence to suggest that it should be distinguished from other variants of IPMNs because of its distinct morphologic appearance, mucin and molecular profiles. In contrast to other IPMNs, IOPN lacks mutations in KRAS and GNAS, but instead exhibits mutations in ARHGAP26, ASXL1, EPHA8, and ERBB4 genes. ${ }^{12,18}$

Invasive carcinoma was found in approximately $30 \%$ of surgically resected IPMNs. ${ }^{19,20}$ The risk factors of an IPMN harboring invasive carcinoma are main-duct type, distal common bile duct dilation, size $>3.0 \mathrm{~cm}$, multicystic lesion, and solid component. Small, branch-duct IPMNs have a low risk of progression and are not recommended for surgical removal. ${ }^{21}$ Among subtypes, the pancreatobiliary type has the most aggressive behavior, whereas the gastric type has the lowest risk of harboring an invasive carcinoma. ${ }^{11}$ Invasive carcinoma arising in IPMNs can have tubular (commonly associated with pancreatobiliary-type IPMN) or colloid morphology (commonly associated with intestinaltype IPMN) (Figure 1, G and H). ${ }^{22}$

The estimated 5-year survival rate of IPMNs with associated invasive carcinoma is approximately $30 \%$ to $50 \%$, which is higher than that of invasive PDACs without IPMNs, but much lower than that of noninvasive IPMNs. Therefore, radiologic correlation, careful gross examination, and adequate sampling of IPMNs are important to confirm the presence of an invasive component in resected specimens. In some institutions, mucinous cystic lesions are entirely submitted for histologic examination to exclude invasive carcinoma.

The rate of recurrence or new disease in the remnant pancreas is $<20 \%$ after partial pancreatectomy. ${ }^{20,23}$ The rate increases to approximately $50 \%$ in patients who had IPMNs with associated invasive carcinoma, and usually as metastatic disease. ${ }^{24}$ Currently, the postoperative recommendation for patients with partial pancreatectomy is surveillance for at least 5 years. ${ }^{25}$

\section{Mucinous Cystic Neoplasm}

MCN is a radiologically and grossly identified mucinous cystic lesion. MCN is different from IPMN in several aspects. First, MCN does not communicate with the pancreatic ductal system. Second, MCN is lined by neoplastic mucinous columnar epithelium and pathognomonic ovarian-type spindle cell stroma. MCNs commonly occur in the tail of the pancreas and exclusively in women with a mean age of 50 years. ${ }^{26}$ Some MCNs are incidental findings, whereas others cause abdominal pain and fullness. Because they do not communicate with pancreatic duct, patients with $\mathrm{MCN}$ are less likely to have pancreatitis, jaundice, or new-onset diabetes mellitus compared with those with IPMN. Radiologic features favoring MCN are solitary cyst with thick wall, internal septations, and peripheral calcifications. ${ }^{27}$

Grossly, MCN is a single multilocular cyst with a thick and fibrotic capsule. Solid areas within the cyst or at the capsule should be sampled extensively for the presence of an invasive component. The lining epithelium consists of columnar cells with abundant apical mucin. Intestinal-type epithelium with goblet cells can sometimes be seen in MCN. The underlying ovarian-type stroma should be present for the diagnosis of MCN (Figure 1, I and J). Stromal hyalinization resembling ovarian corpora albicans can be seen in the stroma. ${ }^{28}$

Epithelial cells of MCN express cytokeratin and glycoprotein markers, such as CEA and CA19-9. MUC5AC is expressed diffusely, whereas MUC2 expression is seen in intestinal-type epithelium. MUC1 is usually detected in invasive carcinomas arising from MCNs. In addition to estrogen and progesterone receptors, the stromal cells also frequently express inhibin. ${ }^{28}$

The criteria for evaluating dysplasia in IPMN also apply to MCN. MCN is classified into low and high grade (Figure 1, I and J).

Frequent genetic alterations identified in other precursor lesions are also identified in MCN, including $K R A S, T P 53$, $S M A D 4$, and $C D K N 2 A$. Approximately half of mucinous cystic neoplasms harbor the RNF43 mutation. In contrast to IPMN, GNAS mutation is not found in MCN. There is no specific genetic mutation in $\mathrm{MCN}$; therefore, the preoperative diagnosis requires exclusion of other pancreatic cystic lesions.

Invasive pancreatic carcinoma is found in approximately $15 \%$ to $30 \%$ of $\mathrm{MCN}$ cases, and they have a better prognosis than conventional PDAC. ${ }^{20,26,27}$ The risk of invasive carcinoma arising from MCNs increases with age. Radiologic features suggestive of an associated invasive carcinoma include large cyst size, thickening of septae, and the presence of an intracystic solid mass. ${ }^{26,27}$ In contrast to IPMN, patients with noninvasive $\mathrm{MCN}$ have a 5-year survival rate of nearly $100 \%$; therefore, postoperative follow-up is usually not necessary. MCN with associated minimally invasive adenocarcinoma, defined as invasion into the ovarian-type stroma but not into the pancreatic parenchyma, demonstrates good prognosis with rare recurrence. $^{29}$ The 5-year survival rate for patients with MCN with invasive carcinoma is $25 \%$ to $35 \% .^{20,26}$ The single most important factor for pathologic evaluation of MCN is to confirm or exclude the presence of an invasive component, similar to the assessment of IPMNs. Therefore, extensive sampling is essential in the evaluation of MCN. $^{26}$ 


\section{Intraductal Tubulopapillary Neoplasm}

ITPN is a rare intraductal epithelial neoplasm and is recognized as a distinct entity in World Health Organization classification. ITPN can be detected radiologically and grossly. ITPN occurs almost equally in both sexes and is commonly diagnosed in patients between 35 and 78 years of age (mean age, 61 years). ${ }^{30}$ It is difficult to differentiate ITPN from IPMN by imaging alone because of overlapping features, but a more solid growth pattern favors ITPN over IPMN. A cork-of-wine-bottle sign is a characteristic feature observed on magnetic resonance cholangiopancreatography and endoscopic retrograde cholangiopancreatography, which indicates intraductal growth. ${ }^{31}$ Approximately $95 \%$ of ITPNs arise in the main pancreatic duct, whereas a small number arises in branch ducts. ${ }^{32}$

The size of ITPN ranges from 1 to $15 \mathrm{~cm}$ (average size, 3 $\mathrm{cm}$ ). Approximately $50 \%$ of ITPNs are located in the head of pancreas, $33 \%$ in the body and/or tail, and $>10 \%$ in the pancreatic duct with diffuse involvement. ${ }^{30}$ ITPN is defined as a macroscopic $(\geq 1 \mathrm{~cm})$, intraductal, tubule-forming epithelial mass lesion with high-grade dysplasia. Histologically, ITPN consists of closely packed tubules with focal areas of papillary and cribriform structures and with none to minimal mucin (Figure $1 \mathrm{~K}$ ). The neoplastic cells are cuboidal to low columnar with a moderate amount of cytoplasm and with moderately to severely atypical nuclei. Apical snouts, intraluminal secretion, or comedo-like necrosis can be observed in some cases. Clear cell changes, stromal osseous, and cartilaginous metaplasia have been reported in ITPN. ${ }^{33}$

The neoplastic cells of ITPN are positive for cytokeratin 7, cytokeratin 19, MUC1, and MUC6; and they are negative for MUC2, MUC5AC, trypsin, and $\beta$-catenin. ${ }^{30}$ MUC6 and MUC5AC are useful in differentiating ITPNs from IPMNs because most IPMNs are MUC5A ${ }^{+} / \mathrm{MUC6}^{-}$, whereas ITPNs are $\mathrm{MUC6}^{+} / \mathrm{MUC}^{-} \mathrm{A}^{-}$. An exception is IOPN, which has a similar mucin profile to ITPN $\left(\mathrm{MUC6}^{+} \mathrm{MUC1}^{+}\right.$/ MUC5 $\mathrm{A}^{-} \mathrm{MUC}^{-33}$ ), and this may imply that ITPN is more closely related to IOPN than other subtypes of IPMN.

Although ITPN has overlapping macroscopic and histologic features with IPMN, molecular studies support the concept of ITPN and IPMN as two separate entities given their distinct molecular genetic profiles. In contrast to IPMNs, in which the KRAS mutations are more common, the PIK3CA mutation is more common in ITPNs (up to $27 \%$ ), which suggests that activation of the phosphatidylinositol 3-kinase-AKT signaling pathway plays a role in the pathogenesis of ITPNs. KRAS mutation occurs at a relatively low frequency in ITPNs $(0 \%$ to $10 \%)$. A nextgeneration sequencing study of 11 cases of ITPN revealed mutations in histone $\mathrm{H} 3$ methyltransferase genes, MLL2 and MLL3, and MCL1 (a member of the Bcl-2 family) amplification. $^{18}$

Approximately $50 \%$ of the ITPNs are associated with invasive carcinoma. Therefore, adequate sampling and careful microscopic examination are essential for the identification of an invasive component. ${ }^{30,34}$ Male, large tumor size, and high Ki-67 proliferation index are risk factors associated with invasive carcinoma. ${ }^{30}$ Postoperative recurrence and liver metastasis of ITPN have been reported. ${ }^{33}$ The 5-year survival rate of patients with ITPN-associated invasive carcinoma is $>30 \%$, which is better than conventional PDAC. ${ }^{21}$

ITPN shares overlapping morphologic features with pancreatobiliary IPMN and IOPN. Papillary architecture and abundant mucin production support the diagnosis of IPMN, whereas solid intraductal mass, tubular architecture, minimal mucin, and luminal comedo-like necrosis favor ITPN. Another less common differential diagnosis is intraductal acinar cell carcinoma, which consists of sheets of back-toback acinar structures with neoplastic cells demonstrating acinar differentiation (positive for trypsin, chymotrypsin, and BCL-10 on immunohistochemical stains). ${ }^{35,36}$

\section{Cytopathology of Pancreatic NMCs, Including IPMNs and MCNs}

Pancreatic cysts are detected in $2.4 \%$ to $13 \%$ of abdominal imaging, ${ }^{37}$ and they can be categorized as nonneoplastic cysts, neoplastic cysts, and solid tumors with cystic change. Malignant risk of neoplastic cysts is variable. A nonmucinous neoplastic cyst, such as serous cystadenoma, is commonly benign, whereas neoplastic mucinous cysts (NMCs), including IPMN and MCN, are considered premalignant neoplasms. A multimodal approach, which combines clinical and radiologic information, cytologic evaluation, and ancillary tests, is required for accurate classification of pancreatic cysts.

Imaging modalities, such as computed tomography and magnetic resonance, yield $40 \%$ to $60 \%$ accuracy in classifying pancreatic cysts. ${ }^{38}$ EUS-FNA cytology has added significant value to imaging studies in assessing the risk of malignancy of pancreatic cysts. ${ }^{39}$

The Papanicolaou Society of Cytopathology guidelines classify neoplastic mucinous cysts in category IV. ${ }^{40,41}$ According to the guidelines, diagnostic criteria for NMC include one of the followings: thick colloid-like extracellular mucin, elevated CEA ( $>192 \mathrm{ng} / \mathrm{mL}), K R A S / G N A S$ mutation, or presence of neoplastic mucinous epithelial cells. $^{40}$

EUS-FNA is performed through the duodenal wall if the lesion is located at the pancreatic head. A transgastric method will be used if the lesion is at body or tail. Knowing the relevant endoscopic approach, the pathologist will recognize normal gastric or duodenal epithelium as procedure-associated contaminants and not as lesional material. Thick colloid-like mucin with or without lining epithelium of the cyst is diagnostic of a neoplastic mucinous cyst. Mucin with cellular or inflammatory debris is also associated with mucinous cysts. 
Table 1 Cytologic Features of Low- and High-Grade Atypia in NMC

\begin{tabular}{ll}
\hline Cytologic features of low-grade atypia in NMC & Cytologic features of high-grade atypia in NMC \\
\hline - Low cellularity & - Low to high cellularity \\
- Single cells, small groups or flat sheets of bland-appearing & - Single cells, small to large three-dimensional crowded cluster \\
glandular epithelial cells ( $\geq 12-\mu$ m duodenal enterocyte) & $\begin{array}{l}(<12-\mu m \text { duodenal enterocyte); papillary architecture } \\
\text { (support IPMN) }\end{array}$ \\
& - Nuclear hypochromasia or hyperchromasia, with or without \\
- Nuclei round and regular with even chromatin and & prominent nucleoli, and nuclear membrane irregularity \\
inconspicuous to occasional discernible nucleoli & - High N/C ratio \\
- Low N/C ratio & $\begin{array}{l}\text { Variable amount of cytoplasm with or without } \\
\text { - Apical cytoplasmic mucin and basally located nuclei; }\end{array}$ \\
the cells may be indistinguishable from gastric contamination & visin or vacuoles; variable cellular necrosis in \\
& the background
\end{tabular}

IPMN, intraductal papillary mucinous neoplasm; N/C, nuclear/cytoplasmic; NMC, neoplastic mucinous cyst.

CEA level analysis of the cystic fluid can add diagnostic value. Brugge et $\mathrm{al}^{42}$ showed that an elevated CEA $>192 \mathrm{ng} /$ $\mathrm{mL}$ is the optimal threshold level for distinguishing mucinous cysts from nonmucinous cysts with $75 \%$ sensitivity and $84 \%$ specificity. Van der Waaij et al ${ }^{43}$ showed that a higher cutoff level of $>800 \mathrm{ng} / \mathrm{mL}$ is associated with higher specificity (98\%), but low sensitivity (48\%). Nevertheless, an increased level of CEA cannot absolutely distinguish a benign from a neoplastic mucinous cyst, and a low level of CEA cannot absolutely exclude a mucinous cyst. ${ }^{40}$

There are many overlapping features between IPMN and MCN in EUS-FNA cytology specimens. Distinguishing these two entities solely based on cytologic evaluation alone is almost impossible; it often requires clinical and radiologic correlation. The subepithelial ovarian stroma, a diagnostic feature of MCN, is often not sampled in cytology aspirates. Studies have shown that molecular analysis for KRAS and NRAS mutations can add values in diagnosing NMC. ${ }^{44-46}$ The presence of KRAS mutations supports a mucinous cyst, but a KRAS mutation alone cannot separate premalignant cysts (NMCs with low-grade atypia) from malignant cysts (NMCs with high-grade atypia or associated invasive carcinoma). ${ }^{47}$ A combined analysis of KRAS mutation, loss of heterozygosity, and DNA quantity/quality correlates well with malignant cysts. ${ }^{44}$ Both IPMN and MCN commonly harbored mutations in $K R A S$ and $R N F 43$, whereas a GNAS mutation was only found in IPMN, but not in MCN. ${ }^{45,46}$ Therefore, the presence of a GNAS mutation, in addition to a KRAS mutation, supports the diagnosis of IPMN. ${ }^{45,46,48}$ Similar to a KRAS mutation, alterations in RNF43 and GNAS cannot distinguish high-grade or invasive from lowgrade IPMNs ${ }^{45,46}$ However, Singhi et $\mathrm{al}^{49}$ recently reported that combination of $K R A S$ and/or GNAS mutation with TP53, PIK3CA, and/or PTEN alterations detected in cystic aspirate can predict NMC with advanced neoplasia (highgrade dysplasia or invasive adenocarcinoma) with $79 \%$ sensitivity and $96 \%$ specificity.

Once the presence of NMC is determined, cytologic grading of neoplastic mucinous epithelium becomes necessary. A two-tier system for grading epithelial atypia has been recommended by the Papanicolaou Society of Cytopathology, which includes low-grade atypia (low- and intermediate-grade dysplasia) and high-grade atypia (highgrade dysplasia or worse). ${ }^{40,50}$

Low-grade NMC aspirate often shows low cellularity. Cytologic features of low-grade neoplastic epithelium are single cells, small groups, or flat sheets of bland-appearing glandular epithelial cells with apical cytoplasmic mucin and basally located nuclei, which are often difficult to distinguish from gastrointestinal epithelium contaminant (Table 1)..$^{40,51}$

High-grade NMC aspirate tends to be more cellular. The neoplastic cells are often smaller than duodenal enterocytes with an increased nuclear/cytoplasmic ratio, nuclear hypochromasia or hyperchromasia, prominent nucleoli, and nuclear membrane irregularity. They are arranged in single cells or in small to large crowded clusters. Variable cellular necrosis is often present in the background (Figure 2). ${ }^{39,50,52}$ Identification of high-grade dysplastic cells is important because surgical management is recommended for highgrade lesions. ${ }^{20}$

\section{Invasive Pancreatic Ductal Adenocarcinoma}

Pancreatic ductal adenocarcinoma is the most common histologic subtype of pancreatic malignancy, comprising almost $90 \%$ of all malignant pancreatic neoplasms. ${ }^{5}$ The mean age of patients at diagnosis is 66 years. ${ }^{1}$ At the time of diagnosis, most patients are inoperable because of locally advanced disease or distant metastasis. The median survival for patients with distant metastasis is $<1$ year. ${ }^{53}$ PDAC commonly presents as a hypoechoic solid mass with an irregular border. Most PDACs occur in the pancreatic head (60\% to $70 \%)$, and the rest are in the body (5\% to $15 \%$ ) or tail $(10 \%$ to $15 \%)$. ${ }^{4}$ Various imaging studies, including ultrasonography, computed tomography, magnetic resonance imaging, and EUS, are used to evaluate pancreatic solid 

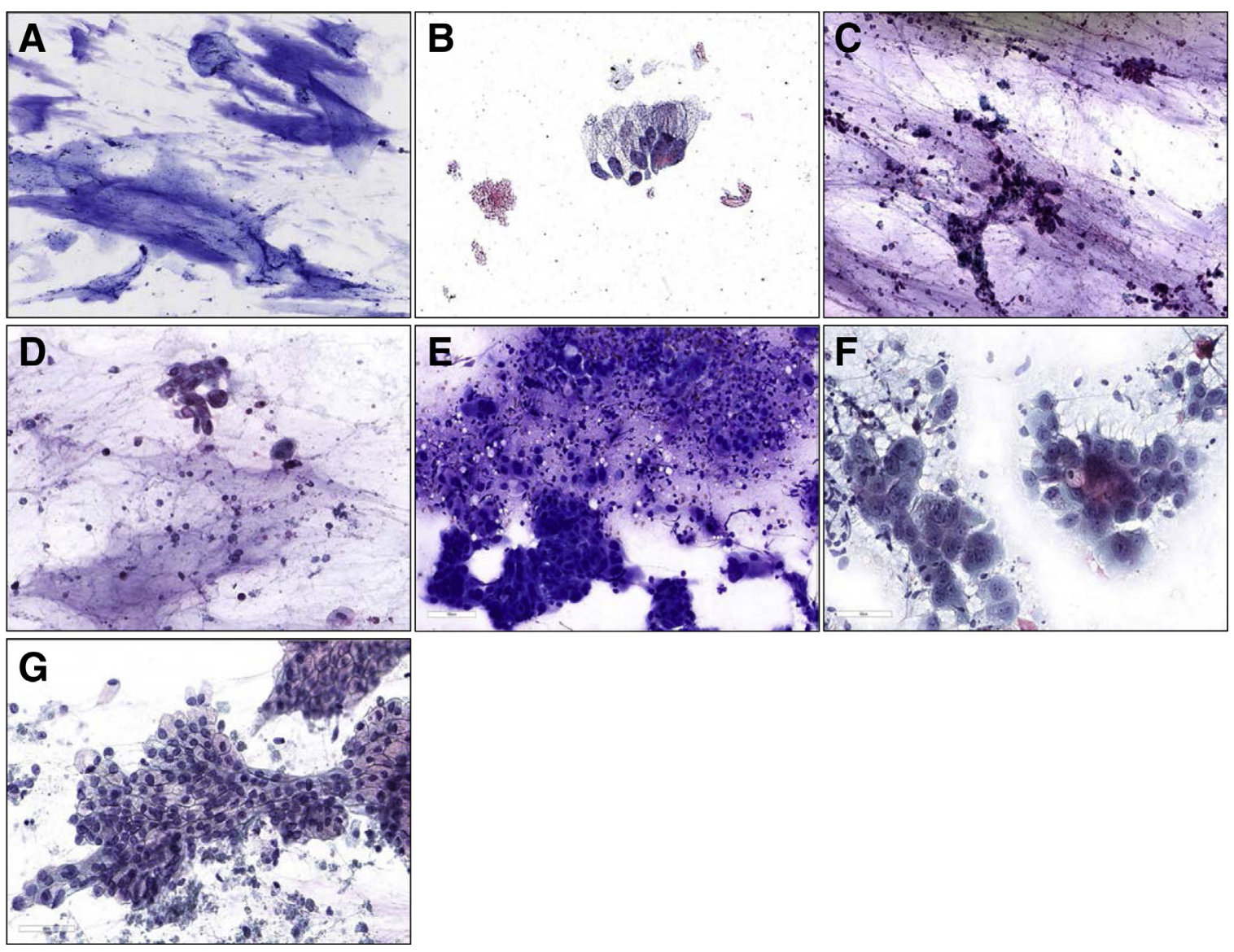

Figure 2 A: Thick colloid-like mucin (Diff-Quick stain). B: Low-grade neoplastic mucinous cysts (NMCs) show a small group of bland-appearing glandular epithelial cells with apical cytoplasmic mucin, basally located nuclei, and low nuclear/cytoplasmic (N/C) ratio (Papanicolaou stain). C and D: High-grade NMC shows neoplastic cells arranged in crowded clusters with high N/C ratio, nuclear hypochromasia or hyperchromasia, and nuclear membrane irregularity. Cellular necrosis and mucin are present in the background (Papanicolaou stain). E and F: Poorly differentiated ductal adenocarcinoma with marked nuclear pleomorphism, macronucleoli, and high N/C ratio [Diff-Quick stain (E) and Papanicolaou stain (F)]. G: Well-differentiated ductal adenocarcinoma with abundant mucin in the cytoplasm, low $\mathrm{N} / \mathrm{C}$ ratio, and disorganized cell arrangement resembling a drunken honeycomb (Papanicolaou stain). Original magnification: $\times 20$ (A); $\times 400($ B-D, F, and G); $\times 200($ E).

lesions. Other benign pancreatic lesions (ie, chronic and autoimmune pancreatitis) can mimic pancreatic malignancy clinically and radiologically. ${ }^{54,55}$ It is difficult to distinguish benign mass-forming pancreatitis from malignant lesions solely based on radiographic appearance. Cytohistologic tissue evaluation remains the gold standard in diagnosing pancreatic malignancy.

Grossly, PDACs are firm, ill-defined white-yellow infiltrative lesions. The main pancreatic duct and distal common bile duct upstream of the lesion are usually dilated because of duct obstruction. Fibrosis and atrophy are common in PDAC, which sometimes obscure the demarcation between invasive carcinoma and chronic pancreatitis regions.

Microscopically, conventional PDAC is composed of haphazardly arranged infiltrating glandular and ductal structures, surrounded by desmoplastic stroma. Invasive glands are frequently identified well beyond the grossly identified border of the lesion. Poorly differentiated PDAC is composed of irregular and smaller glands with marked cellular pleomorphism. Well-differentiated invasive carcinomas may have bland glands, which is difficult to distinguish from reactive glands in areas of chronic pancreatitis. Histologic criteria of invasive adenocarcinoma are haphazard arrangement of neoplastic glands, perineural invasion, vascular invasion, gland immediately adjacent to a muscular artery, luminal necrosis, incomplete lumina, nuclear variation $(>4: 1)$ in a single gland, isolated gland in peripancreatic adipose tissue, and atypical mitoses. ${ }^{56}$ Neoplastic cells can replace endothelial cells of small vessels and reendothelialize these vessels, which can mimic PanIN. Identification of a well-defined smooth muscle layer can determine whether a neoplastic gland is in a vessel. ${ }^{57}$

Most PDACs demonstrate immunoreactivities to antibodies of several cytokeratins $(7,8,18,19$, and 20), several types of mucin (MUC1, MUC3, MUC4, and MUC5AC), and cancer marker antigens (CEA, B72.3, CA19-9, mesothelin, and S-100A4). ${ }^{28,58}$ There is no definite marker to distinguish PDAC from benign ductal structures. Aberrant p53 expression and loss of SMAD4 expression (in 55\% of PDACs) support the diagnosis of PDAC, but absent p53 
Table 2 Comparison of Staging Definitions of Pancreatic Carcinoma in the Seventh and Eighth Editions of the AJCC Cancer Staging Manuals

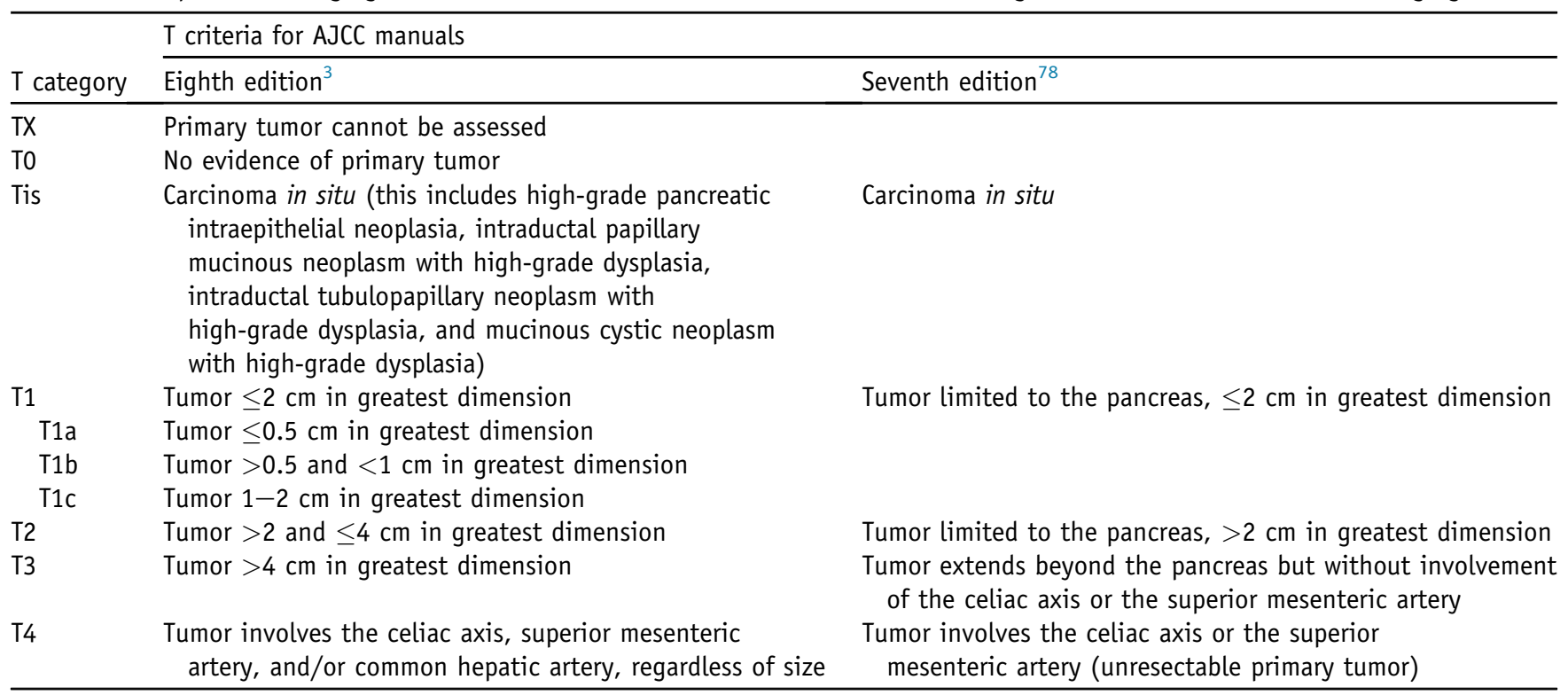

AJCC, American Joint Committee on Cancer.

immunostaining or maintained SMAD4 expression does not exclude PDAC. ${ }^{59}$

The recent development of large-scale genome sequencing studies provides insights in genetic alteration of PDAC. On average, PDAC has 50 to 80 exomic nonsilent mutations. Larger structural variations, including intrachromosomal rearrangement, deletions, and amplifications, are also common in PDAC. ${ }^{60}$ Mutation of the KRAS oncogene occurs early in neoplastic progression and is observed in almost all precursor lesions of PDAC, even in low-grade PanIN and in $>90 \%$ of PDACs. Subsequent mutations that drive neoplastic progression are tumor suppressor genes, such as CDKN2A, TP53, and SMAD4. Further accumulation of genetic and epigenetic alterations drives neoplastic progression of precursor lesions into invasive carcinoma. ${ }^{61}$ Most PDACs harbor abnormalities in $C D K N 2 A$ because of mutation or hypermethylation of the promoter region. A TP53 mutation occurs in 50\% of PDACs, and loss of SMAD4 expression is observed in $55 \%$ of PDACs. ${ }^{60,62}$ Loss of SMAD4 is associated with poor prognosis, whereas mutations in chromatin-regulating genes (MLL, MLL2, MLL3, and ARID1A) are associated with improved survival. ${ }^{62-64}$ Clinical trials targeting specific pathways and mutations in PDAC are being conducted. The development of personalized treatment may drastically change the outcome of this disease. In addition to genetic alterations, tumor microenvironment also plays an important role in PDAC. ${ }^{65,66}$ Tumor stromal expression profile was found to have prognostic significance. ${ }^{67}$ Distinct immune cell populations are present in the PDAC microenvironment, which affect tumor progression and therapeutic outcomes. Regulatory $\mathrm{T}$ cells likely play a role in the early stage of disease, and high intratumoral regulatory $\mathrm{T}$ cell/CD4 ${ }^{+} \mathrm{T}$ cell ratio is a prognostic factor of poor survival. Investigation is underway in targeting regulatory $\mathrm{T}$ cells in malignancy. ${ }^{68,69}$

The prognosis of PDAC is poor, with an overall 5-year survival rate at approximately $8 \%$. Surgical resection is the only curative modality, ${ }^{70}$ but only $20 \%$ of PDACs are resectable at the time of diagnosis. The 5-year survival rate for patients after surgery ranges from $3 \%$ to $31 \%$, depending on clinical stage, and the median survival time after resection is 12 to 18 months. $^{71}$ Initial borderline and nonresectable PDACs may be down-staged to resectable tumors in approximately $30 \%$ to $40 \%$ of patients after neoadjuvant chemotherapy. ${ }^{72}$ Only $3 \%$ of patients survive after 8 years. In the past decade, several landmark trials in the treatment of PDAC have been published and have brought some optimism. Studies showed that as monotherapy, FOLFIRINOX (leucovorin calcium, fluorouracil, irinotecan hydrochloride, and oxaliplatin) provides a survival benefit of $>4$ months compared with gemcitabine, but with higher toxicity. Nab-paclitaxel has demonstrated antitumor activity, and the combination of gemcitabine and nab-paclitaxel has become another first-line option for patients. Nanoliposomal irinotecan in combination with fluorouracil/leucovorin has recently been approved for second-line treatment. ${ }^{73}$ There is also evidence that a small proportion of PDACs that are deficient for mismatch repair system benefit from immunotherapy, such as pembrolizumab. ${ }^{74}$

The main differential diagnosis for conventional ductal adenocarcinoma is the distinction of a well-differentiated carcinoma from reactive ductules in atrophic chronic pancreatitis. Invasive glands are usually distributed haphazardly, whereas benign ductules in areas of chronic pancreatitis retain lobular configuration. The cytoplasm of tumor cells is more eosinophilic than in benign conditions. 
Table 3 Comparison of Cytologic Features of PDAC and Chronic Pancreatitis

\begin{tabular}{ll}
\hline Cytologic features for PDAC & Cytologic features for chronic pancreatitis or autoimmune pancreatitis \\
\hline - Moderate to high cellularity & - Low cellularity \\
- Overlapping nuclei/three-dimensional crowded & - Flat, cohesive sheets with evenly spaced or slightly crowded nuclei \\
groups; disorganization (drunken honeycomb) & \\
- Isolated single cells & - Absent (or only rare) isolated atypical cells \\
- Nuclear enlargement, anisonucleosis & - Enlarged nuclei, but little variation in size (<4:1 diameter ratio) \\
- Macronucleoli; irregular chromatin distribution $>4$ variation in diameter) & - Discernible nucleoli but not macronucleoli; round to \\
(clumping and parachromatin clearing); nuclear & oval nucleus and smooth nuclear membranes; low $\mathrm{N} / \mathrm{C}$ ratio \\
membrane irregularity; increased N/C ratios & - No cytoplasmic mucin vacuoles \\
- Cytoplasmic mucin vacuoles & - Background inflammation, fat necrosis, calcific debris; rare mitosis \\
- Tumor cells embedded in desmoplastic stromal fragments & - Cellular stromal fragments (especially autoimmune pancreatitis) \\
\hline
\end{tabular}

N/C, nuclear/cytoplasmic; PDAC, pancreatic ductal adenocarcinoma.

Perineural or vascular invasion, invasion into the duodenal muscular wall or stroma adjacent to a muscular vessel, ${ }^{75,76}$ and isolated glands in the peripancreatic soft tissue $\mathrm{e}^{77}$ are diagnostic of carcinoma. Additional differential diagnosis includes other histologic subtypes of pancreatic neoplasms and metastasis.

\section{Update of Tumor Staging and Surgical Pathology Report of PDAC}

Post-resection prognosis of patients with pancreatic carcinoma is primarily determined by anatomical extent of the disease, as defined by TNM staging. According to the newly published eighth edition of the AJCC Cancer Staging Manual (AJCC, eighth edition), ${ }^{3}$ the T categories (T1 to T3) are defined by the tumor size instead of the extent of tumor invasion, as in the AJCC, seventh edition ${ }^{78}$ (Table 2). The new $\mathrm{T}$ categories allow a more reproducible system of $\mathrm{T}$ staging and provide better prognostic stratification. ${ }^{3}$ For invasive carcinoma associated with precursor lesions, size of invasive component should be used to determine $\mathrm{T}$ stage. In cases of multifocal invasion, maximum linear dimension of the largest invasive focus should be used for staging.

In the setting of neoadjuvant therapy, gross assessment of tumor size may not always correlate with microscopic measurement of residual tumor. Scattered residual tumor glands may disperse within a large fibrotic tumor bed, which complicates the assessment of tumor size. Currently, there is no consensus guideline or protocol to guide gross and microscopic evaluation of pancreatic cancer after neoadjuvant therapy. Hartman and Krasinskas ${ }^{79}$ suggested that if the tumor bed is $\leq 3 \mathrm{~cm}$, the entire tumor bed should be submitted for microscopic examination, and if the tumor bed is $\geq 3 \mathrm{~cm}$, sections should be submitted serially at $0.5-\mathrm{cm}$ intervals along the largest dimension of the tumor bed. If no residual tumor is identified in the initial sections, then the entire tumor bed should be submitted for microscopic examination. ${ }^{79,80}$ Pai and $\mathrm{Pai}^{80}$ noticed that tumor in the duodenal wall is often not affected by neoadjuvant therapy; therefore, sampling of duodenal wall adjacent to the tumor bed should be performed.

The $\mathrm{N}$ stage was changed from two categories in the AJCC, seventh edition (NO with no nodal metastasis and N1 with positive nodes) into three categories in the AJCC, eighth edition, to provide better prognostic stratification: NO with no positive nodes, N1 with one to three positive nodes, and N2 with four or more positive nodes. Microscopic examination of at least 12 regional lymph nodes is recommended. ${ }^{81,82}$

Standardized assessment of resection margins in pancreaticoduodenectomy specimens is important. Resection margin with tumor cells at or within $1 \mathrm{~mm}$ is considered a positive margin. ${ }^{83}$ Adsay et $\mathrm{al}^{84}$ recommended submitting the uncinate margin entirely for histologic examination, given that grossly invisible tumor is often seen in this area and the poor prognosis of a positive uncinate margin. Vascular groove is the site of the confluence of portal and superior mesenteric veins and is often considered as a margin. Although not considered true margins, status of anterior and nonuncinate posterior surface involvement needs to be included in the surgical pathologic report.

\section{Cytopathology of PDAC}

EUS-FNA biopsy is widely used in pathologic diagnosis of pancreatic tumors with high sensitivity and specificity. ${ }^{85}$ In most institutions, a rapid on-site evaluation is performed to increase the diagnostic yield of solid mass and to reduce nondiagnostic rate.

EUS-FNA biopsy of normal pancreas parenchyma consists predominantly of cohesive, grapelike groups of acinar cells, and a few flat sheets of bland, evenly distributed ductal epithelial cells. Aspirates of pancreatic adenocarcinoma are often highly cellular. The background can be clean, necrotic, inflammatory, or mucinous. Neoplastic ductal epithelial cells are arranged in groups, forming sheets, clusters, and three-dimensional aggregates. Several 
distinct nuclear features are diagnostic of pancreatic adenocarcinomas, ${ }^{86}$ such as nuclear pleomorphism, hyperchromasia, macronucleoli, high nuclear/cytoplasmic ratio, and nuclear overlapping and irregular nuclear membranes (Figure 2). High-grade ductal adenocarcinoma often shows more overt features of malignancy, making the diagnosis straightforward. Single isolated tumor cells and mitosis are commonly seen in the background of a high-grade tumor. On the other hand, well-differentiated tumor cells have less nuclear pleomorphism, low nuclear/cytoplasmic ratio, and abundant intracellular mucin. The cells arranged in sheets become disorganized, not evenly spaced, resembling a drunken honeycomb. Marked anisonucleosis ( $>4: 1$ variation in diameter) can be a helpful feature (Table 3). Demonstrating an invasion into desmoplastic stroma in cell blocks from aspirates or core biopsy specimens can also aid the final diagnosis.

When cytomorphologic features are qualitatively or quantitatively insufficient for making a definitive malignant diagnosis, atypical or suspicious for malignancy can be rendered. The cytologic or architectural features in the atypical category are beyond those associated with reactive changes, but insufficient in the degree or quantity to be categorized as either neoplastic or suspicious for malignancy. ${ }^{40}$ The suspicious for malignancy category is defined as a sample with significant cytologic or architectural atypia suggestive of malignancy, but qualitatively or quantitatively insufficient for a definitive diagnosis. ${ }^{40}$

In chronic or autoimmune pancreatitis, the FNA specimen is hypocellular, containing a few clusters of ductal epithelial cells with reactive atypia, cellular stromal fragments with crush artifact, and lymphoplasmacytic inflammation (Table 3). Islet cells sometimes can also be seen in the aspirate of chronic pancreatitis. Immunostain for IgG4 can sometimes be helpful for the diagnosis of autoimmune pancreatitis, but serum IgG4 is clinically more diagnostic. If ductal epithelial atypia is concerning for malignancy, immunohistochemical stains for SMAD4 and p53 can be helpful. Loss of SMAD4 expression and strong positivity for p53 support a malignant diagnosis.

\section{Conclusion}

Pancreatic cancer is one of the deadliest diseases, with poor outcomes and short-lived treatment response; therefore, there is an urgent need for early detection and more effective treatment strategies. In the past decade, comprehensive next-generation sequencing analyses have been performed on samples from large cohorts of patients. These studies have defined the genomic landscape of PDAC, identified novel gene mutations involving pancreatic tumorigenesis, and clarified the genetic alterations that underlie multistep tumorigenesis. $^{87}$

Furthermore, genetic alterations can be used to develop diagnostic markers for early detection, biomarkers for predicting disease progression or therapeutic response, and novel targets for therapies.

The evolutionary patterns of PDAC suggest a 10-year window from an initiating mutation to an invasive disease, which provides a broad time period for early detection. The application of molecular alteration has been used in liquid biopsy of pancreatic lesions, including FNA samples of pancreatic cysts, duodenal fluid collected endoscopically after secretin stimulation, and circulating tumor DNA in peripheral blood. ${ }^{87}$ Molecular analysis of cyst fluid cannot only distinguish neoplastic precursors from benign cystic lesions, but can also identify precursor lesions with highgrade dysplasia and associated invasive carcinoma. Circulating tumor DNA can be detected in patients with metastatic pancreatic cancer and almost half of patients with localized disease. ${ }^{63,88}$ Despite low sensitivity in detection of noninvasive lesions, circulating tumor DNA can be used to detect invasive cancers at an earlier stage and to follow up patients with known cancer. Circulating tumor DNA has the potential to be used as a surrogate for detecting genetic alteration in the main tumor and providing information for prognosis and therapeutic resistance. ${ }^{88}$ These new techniques highlight the promise of early diagnosis of advanced pancreatic cystic lesion and PDAC.

\section{References}

1. Siegel RL, Miller KD, Jemal A: Cancer statistics, 2018. CA Cancer J Clin 2018, 68:7-30

2. Rahib L, Smith BD, Aizenberg R, Rosenzweig AB, Fleshman JM, Matrisian LM: Projecting cancer incidence and deaths to 2030: the unexpected burden of thyroid, liver, and pancreas cancers in the United States. Cancer Res 2014, 74:2913-2921

3. Kakar S, Pawlik TM, Allen PJ, Vauthey J-N: Exocrine pancreas Edited by Amin MB, Edge S, Greene F, Byrd DR, Brookland RK, Washington MK, Gershenwald JE, Compton CC, Hess KR, Sullivan DC, Jessup JM, Brierley JD, Gaspar LE, Schilsky RL, Balch CM, Winchester DP, Asare EA, Madera M, Gress DM, Meyer LR. In AJCC Cancer Staging Manual. ed 8. New York, NY: Springer, 2017. pp. 337-347

4. Bosman FT, Carneiro F, Hruban RH, Theise ND: WHO Classification of Tumours of the Digestive System. Lyon, France: International Agency for Research on Cancer (IARC), 2010. pp. 279-334

5. Basturk O, Hong SM, Wood LD, Adsay NV, Albores-Saavedra J, Biankin AV, Brosens LA, Fukushima N, Goggins M, Hruban RH, Kato Y, Klimstra DS, Kloppel G, Krasinskas A, Longnecker DS, Matthaei H, Offerhaus GJ, Shimizu M, Takaori K, Terris B, Yachida S, Esposito I, Furukawa T: A revised classification system and recommendations from the Baltimore Consensus Meeting for neoplastic precursor lesions in the pancreas. Am J Surg Pathol 2015, 39:1730-1741

6. Lohr M, Kloppel G, Maisonneuve P, Lowenfels AB, Luttges J: Frequency of K-ras mutations in pancreatic intraductal neoplasias associated with pancreatic ductal adenocarcinoma and chronic pancreatitis: a meta-analysis. Neoplasia 2005, 7:17-23

7. Hosoda W, Chianchiano P, Griffin JF, Pittman ME, Brosens LA Noe M, Yu J, Shindo K, Suenaga M, Rezaee N, Yonescu R, Ning Y, Albores-Saavedra J, Yoshizawa N, Harada K, Yoshizawa A, Hanada K, Yonehara S, Shimizu M, Uehara T, Samra JS, Gill AJ, Wolfgang CL, Goggins MG, Hruban RH, Wood LD: Genetic analyses of isolated high-grade pancreatic intraepithelial neoplasia 
(HG-PanIN) reveal paucity of alterations in TP53 and SMAD4. J Pathol 2017, 242:16-23

8. Rezaee N, Barbon C, Zaki A, He J, Salman B, Hruban RH, Cameron JL, Herman JM, Ahuja N, Lennon AM, Weiss MJ, Wood LD, Wolfgang CL: Intraductal papillary mucinous neoplasm (IPMN) with high-grade dysplasia is a risk factor for the subsequent development of pancreatic ductal adenocarcinoma. HPB (Oxford) 2016, 18:236-246

9. Silas AM, Morrin MM, Raptopoulos V, Keogan MT: Intraductal papillary mucinous tumors of the pancreas. AJR Am J Roentgenol 2001, 176:179-185

10. Yamao K, Ohashi K, Nakamura T, Suzuki T, Watanabe Y, Shimizu Y, Nakamura Y, Ozden I: Evaluation of various imaging methods in the differential diagnosis of intraductal papillarymucinous tumor (IPMT) of the pancreas. Hepatogastroenterology 2001, 48:962-966

11. Noe M, Brosens LA: Pathology of pancreatic cancer precursor lesions. Surg Pathol Clin 2016, 9:561-580

12. Basturk O, Chung SM, Hruban RH, Adsay NV, Askan G, IacobuzioDonahue C, Balci S, Zee SY, Memis B, Shia J, Klimstra DS: Distinct pathways of pathogenesis of intraductal oncocytic papillary neoplasms and intraductal papillary mucinous neoplasms of the pancreas. Virchows Arch 2016, 469:523-532

13. Matthaei H, Wu J, Dal Molin M, Shi C, Perner S, Kristiansen G, Lingohr P, Kalff JC, Wolfgang CL, Kinzler KW, Vogelstein B, Maitra A, Hruban RH: GNAS sequencing identifies IPMN-specific mutations in a subgroup of diminutive pancreatic cysts referred to as "incipient IPMNs". Am J Surg Pathol 2014, 38:360-363

14. Tan MC, Basturk O, Brannon AR, Bhanot U, Scott SN, Bouvier N, LaFemina J, Jarnagin WR, Berger MF, Klimstra D, Allen PJ: GNAS and KRAS mutations define separate progression pathways in intraductal papillary mucinous neoplasm-associated carcinoma. J Am Coll Surg 2015, 220:845-854

15. Pittman ME, Rao R, Hruban RH: Classification, morphology, molecular pathogenesis, and outcome of premalignant lesions of the pancreas. Arch Pathol Lab Med 2017, 141:1606-1614

16. Moris D, Damaskos C, Spartalis E, Papalampros A, Vernadakis S, Dimitroulis D, Griniatsos J, Felekouras E, Nikiteas N: Updates and critical evaluation on novel biomarkers for the malignant progression of intraductal papillary mucinous neoplasms of the pancreas. Anticancer Res 2017, 37:2185-2194

17. Joseph L: Telomere diagnostics for pancreatic neoplasms and cysts. J Mol Diagn 2018, 20:31-33

18. Basturk O, Tan M, Bhanot U, Allen P, Adsay V, Scott SN, Shah R, Berger MF, Askan G, Dikoglu E, Jobanputra V, Wrzeszczynski KO, Sigel C, Iacobuzio-Donahue C, Klimstra DS: The oncocytic subtype is genetically distinct from other pancreatic intraductal papillary mucinous neoplasm subtypes. Mod Pathol 2016, 29:1058-1069

19. Strauss A, Birdsey M, Fritz S, Schwarz-Bundy BD, Bergmann F, Hackert T, Kauczor HU, Grenacher L, Klauss M: Intraductal papillary mucinous neoplasms of the pancreas: radiological predictors of malignant transformation and the introduction of bile duct dilation to current guidelines. Br J Radiol 2016, 89:20150853

20. Tanaka M, Fernandez-del Castillo C, Adsay V, Chari S, Falconi M, Jang JY, Kimura W, Levy P, Pitman MB, Schmidt CM, Shimizu M, Wolfgang CL, Yamaguchi K, Yamao K: International consensus guidelines 2012 for the management of IPMN and MCN of the pancreas. Pancreatology 2012, 12:183-197

21. Kloppel G, Basturk O, Schlitter AM, Konukiewitz B, Esposito I: Intraductal neoplasms of the pancreas. Semin Diagn Pathol 2014, 31: 452-466

22. Yamada S, Fujii T, Shimoyama Y, Kanda M, Nakayama G, Sugimoto H, Koike M, Nomoto S, Fujiwara M, Nakao A, Kodera Y: Clinical implication of morphological subtypes in management of intraductal papillary mucinous neoplasm. Ann Surg Oncol 2014, 21:2444-2452

23. Pea A, Yu J, Rezaee N, Luchini C, He J, Dal Molin M, Griffin JF, Fedor H, Fesharakizadeh S, Salvia R, Weiss MJ, Bassi C,
Cameron JL, Zheng L, Scarpa A, Hruban RH, Lennon AM, Goggins M, Wolfgang CL, Wood LD: Targeted DNA sequencing reveals patterns of local progression in the pancreatic remnant following resection of intraductal papillary mucinous neoplasm (IPMN) of the pancreas. Ann Surg 2017, 266:133-141

24. Turrini $\mathrm{O}$, Waters JA, Schnelldorfer $\mathrm{T}$, Lillemoe $\mathrm{KD}$, Yiannoutsos CT, Farnell MB, Sarr MG, Schmidt CM: Invasive intraductal papillary mucinous neoplasm: predictors of survival and role of adjuvant therapy. HPB (Oxford) 2010, 12:447-455

25. Hirono S, Kawai M, Okada K, Miyazawa M, Shimizu A, Kitahata Y, Ueno M, Yanagisawa A, Yamaue H: Long-term surveillance is necessary after operative resection for intraductal papillary mucinous neoplasm of the pancreas. Surgery 2016, 160:306-317

26. Jang KT, Park SM, Basturk O, Bagci P, Bandyopadhyay $S$, Stelow EB, Walters DM, Choi DW, Choi SH, Heo JS, Sarmiento JM, Reid MD, Adsay V: Clinicopathologic characteristics of 29 invasive carcinomas arising in 178 pancreatic mucinous cystic neoplasms with ovarian-type stroma: implications for management and prognosis. Am J Surg Pathol 2015, 39:179-187

27. Brugge WR: Diagnosis and management of cystic lesions of the pancreas. J Gastrointest Oncol 2015, 6:375-388

28. Klimstra DS, Adsay NV: Tumors of the pancreas. Edited by Odze RD, Goldblum JR. In Surgical Pathology of the GI Tract, Liver, Biliary Tract, and Pancreas. ed 3. Philadelphia, PA: Saunders, 2015. pp. $1081-1119$

29. Lewis GH, Wang H, Bellizzi AM, Klein AP, Askin FB, Schwartz LE, Schulick RD, Wolfgang CL, Cameron JL, O'Reilly EM, Yu KH, Hruban RH: Prognosis of minimally invasive carcinoma arising in mucinous cystic neoplasms of the pancreas. Am J Surg Pathol 2013, 37:601-605

30. Kolby D, Thilen J, Andersson R, Sasor A, Ansari D: Multifocal intraductal tubulopapillary neoplasm of the pancreas with total pancreatectomy: report of a case and review of literature. Int J Clin Exp Pathol 2015, 8:9672-9680

31. Motosugi U, Yamaguchi H, Furukawa T, Ichikawa T, Hatori T, Fujita I, Yamamoto M, Motoi F, Kanno A, Watanabe T, Koike N, Koyama I, Kobayashi J, Shimizu M: Imaging studies of intraductal tubulopapillary neoplasms of the pancreas: 2-tone duct sign and corkof-wine-bottle sign as indicators of intraductal tumor growth. J Comput Assist Tomogr 2012, 36:710-717

32. Yoshida Y, Matsubayashi H, Sasaki K, Kanemoto H, Uesaka K, Ono H: Intraductal tubulopapillary neoplasm of the pancreatic branch duct showing atypical images. J Dig Dis 2015, 16:357-361

33. Rooney SL, Shi J: Intraductal tubulopapillary neoplasm of the pancreas: an update from a pathologist's perspective. Arch Pathol Lab Med 2016, 140:1068-1073

34. Suda K, Hirai S, Matsumoto Y, Mogaki M, Oyama T, Mitsui T, Fujibayashi M, Kumazawa K, Kajiwara T: Variant of intraductal carcinoma (with scant mucin production) is of main pancreatic duct origin: a clinicopathological study of four patients. Am J Gastroenterol 1996, 91:798-800

35. Hosoda W, Sasaki E, Murakami Y, Yamao K, Shimizu Y, Yatabe Y: BCL10 as a useful marker for pancreatic acinar cell carcinoma, especially using endoscopic ultrasound cytology specimens. Pathol Int 2013, 63:176-182

36. La Rosa S, Franzi F, Marchet S, Finzi G, Clerici M, Vigetti D, Chiaravalli AM, Sessa F, Capella C: The monoclonal anti-BCL10 antibody (clone 331.1) is a sensitive and specific marker of pancreatic acinar cell carcinoma and pancreatic metaplasia. Virchows Arch 2009, 454:133-142

37. de Jong K, Nio CY, Hermans JJ, Dijkgraaf MG, Gouma DJ, van Eijck CH, van Heel E, Klass G, Fockens P, Bruno MJ: High prevalence of pancreatic cysts detected by screening magnetic resonance imaging examinations. Clin Gastroenterol Hepatol 2010, 8:806-811

38. Kucera JN, Kucera S, Perrin SD, Caracciolo JT, Schmulewitz N, Kedar RP: Cystic lesions of the pancreas: radiologic-endosonographic correlation. Radiographics 2012, 32:E283-E301 
39. Pitman MB, Centeno BA, Daglilar ES, Brugge WR, MinoKenudson M: Cytological criteria of high-grade epithelial atypia in the cyst fluid of pancreatic intraductal papillary mucinous neoplasms. Cancer Cytopathol 2014, 122:40-47

40. Pitman MB, Centeno BA, Ali SZ, Genevay M, Stelow E, MinoKenudson M, Fernandez-del Castillo C, Max Schmidt C, Brugge W, Layfield L: Standardized terminology and nomenclature for pancreatobiliary cytology: the Papanicolaou Society of Cytopathology guidelines. Diagn Cytopathol 2014, 42:338-350

41. Pitman MB, Layfield L: Category IV: neoplastic: other. The Papanicolaou Society of Cytopathology System for Reporting Pancreaticobiliary Cytology. Cham, Switzerland: Springer International Publishing, 2015. pp. 45-62

42. Brugge WR, Lewandrowski K, Lee-Lewandrowski E, Centeno BA, Szydlo T, Regan S, del Castillo CF, Warshaw AL: Diagnosis of pancreatic cystic neoplasms: a report of the cooperative pancreatic cyst study. Gastroenterology 2004, 126:1330-1336

43. van der Waaij LA, van Dullemen HM, Porte RJ: Cyst fluid analysis in the differential diagnosis of pancreatic cystic lesions: a pooled analysis. Gastrointest Endosc 2005, 62:383-389

44. Shen J, Brugge WR, Dimaio CJ, Pitman MB: Molecular analysis of pancreatic cyst fluid: a comparative analysis with current practice of diagnosis. Cancer 2009, 117:217-227

45. Wu J, Jiao Y, Dal Molin M, Maitra A, de Wilde RF, Wood LD, Eshleman JR, Goggins MG, Wolfgang CL, Canto MI, Schulick RD, Edil BH, Choti MA, Adsay V, Klimstra DS, Offerhaus GJ, Klein AP, Kopelovich L, Carter H, Karchin R, Allen PJ, Schmidt CM, Naito Y, Diaz LA Jr, Kinzler KW, Papadopoulos N, Hruban RH, Vogelstein B: Whole-exome sequencing of neoplastic cysts of the pancreas reveals recurrent mutations in components of ubiquitin-dependent pathways. Proc Natl Acad Sci U S A 2011, 108:21188-21193

46. Wu J, Matthaei H, Maitra A, Dal Molin M, Wood LD, Eshleman JR, Goggins M, Canto MI, Schulick RD, Edil BH, Wolfgang CL, Klein AP, Diaz LA Jr, Allen PJ, Schmidt CM, Kinzler KW, Papadopoulos N, Hruban RH, Vogelstein B: Recurrent GNAS mutations define an unexpected pathway for pancreatic cyst development. Sci Transl Med 2011, 3:92ra66

47. Khalid A, Zahid M, Finkelstein SD, LeBlanc JK, Kaushik N, Ahmad N, Brugge WR, Edmundowicz SA, Hawes RH, McGrath KM: Pancreatic cyst fluid DNA analysis in evaluating pancreatic cysts: a report of the PANDA study. Gastrointest Endosc 2009, 69:1095-1102

48. Singhi AD, Nikiforova MN, Fasanella KE, McGrath KM, Pai RK, Ohori NP, Bartholow TL, Brand RE, Chennat JS, Lu X, Papachristou GI, Slivka A, Zeh HJ, Zureikat AH, Lee KK, Tsung A, Mantha GS, Khalid A: Preoperative GNAS and KRAS testing in the diagnosis of pancreatic mucinous cysts. Clin Cancer Res 2014, 20: 4381-4389

49. Singhi AD, McGrath K, Brand RE, Khalid A, Zeh HJ, Chennat JS, Fasanella KE, Papachristou GI, Slivka A, Bartlett DL, Dasyam AK, Hogg M, Lee KK, Marsh JW, Monaco SE, Ohori NP, Pingpank JF, Tsung A, Zureikat AH, Wald AI, Nikiforova MN: Preoperative nextgeneration sequencing of pancreatic cyst fluid is highly accurate in cyst classification and detection of advanced neoplasia. Gut 2018, 67: 2131-2141

50. Pitman MB, Centeno BA, Genevay M, Fonseca R, MinoKenudson M: Grading epithelial atypia in endoscopic ultrasoundguided fine-needle aspiration of intraductal papillary mucinous neoplasms: an international interobserver concordance study. Cancer Cytopathol 2013, 121:729-736

51. Pitman MB: Pancreas and biliary tree. Edited by Cibas ES, Ducatman BS. In Cytology: Diagnostic Principles and Clinical Correlates. ed 4. Philadelphia, PA: Saunders, 2014. pp. 399-422

52. Pitman MB, Yaeger KA, Brugge WR, Mino-Kenudson M: Prospective analysis of atypical epithelial cells as a high-risk cytologic feature for malignancy in pancreatic cysts. Cancer Cytopathol 2013, $121: 29-36$
53. Visser BC, Muthusamy VR, Yeh BM, Coakley FV, Way LW: Diagnostic evaluation of cystic pancreatic lesions. HPB (Oxford) 2008, 10:63-69

54. Putra J, Liu X: Autoimmune pancreatitis: a succinct overview. J Pancreas 2015, 16:239-243

55. Patlas M, Deitel W, Taylor B, Gallinger S, Wilson SR: Focal chronic pancreatitis mimicking pancreatic head carcinoma: are there suggestive features on ultrasound? Can Assoc Radiol J 2007, 58:15-21

56. Hruban RH, Klimstra DS: Adenocarcinoma of the pancreas. Semin Diagn Pathol 2014, 31:443-451

57. Hong SM, Goggins M, Wolfgang CL, Schulick RD, Edil BH, Cameron JL, Handra-Luca A, Herman JM, Hruban RH: Vascular invasion in infiltrating ductal adenocarcinoma of the pancreas can mimic pancreatic intraepithelial neoplasia: a histopathologic study of 209 cases. Am J Surg Pathol 2012, 36:235-241

58. Nagata K, Horinouchi M, Saitou M, Higashi M, Nomoto M, Goto M, Yonezawa S: Mucin expression profile in pancreatic cancer and the precursor lesions. J Hepatobiliary Pancreat Surg 2007, 14:243-254

59. Wilentz RE, Su GH, Dai JL, Sparks AB, Argani P, Sohn TA, Yeo CJ, Kern SE, Hruban RH: Immunohistochemical labeling for dpc4 mirrors genetic status in pancreatic adenocarcinomas: a new marker of DPC4 inactivation. Am J Pathol 2000, 156:37-43

60. Waddell N, Pajic M, Patch AM, Chang DK, Kassahn KS, Bailey P, et al: Whole genomes redefine the mutational landscape of pancreatic cancer. Nature 2015, 518:495-501

61. Brosens LA, Hackeng WM, Offerhaus GJ, Hruban RH, Wood LD: Pancreatic adenocarcinoma pathology: changing "landscape". J Gastrointest Oncol 2015, 6:358-374

62. Biankin AV, Waddell N, Kassahn KS, Gingras MC, Muthuswamy LB, Johns AL, et al: Pancreatic cancer genomes reveal aberrations in axon guidance pathway genes. Nature 2012, 491: 399-405

63. Sausen M, Phallen J, Adleff V, Jones S, Leary RJ, Barrett MT, Anagnostou V, Parpart-Li S, Murphy D, Kay Li Q, Hruban CA, Scharpf R, White JR, O'Dwyer PJ, Allen PJ, Eshleman JR, Thompson CB, Klimstra DS, Linehan DC, Maitra A, Hruban RH, Diaz LA Jr, Von Hoff DD, Johansen JS, Drebin JA, Velculescu VE: Clinical implications of genomic alterations in the tumour and circulation of pancreatic cancer patients. Nat Commun 2015, 6:7686

64. Jones S, Zhang X, Parsons DW, Lin JC, Leary RJ, Angenendt P, et al: Core signaling pathways in human pancreatic cancers revealed by global genomic analyses. Science 2008, 321:1801-1806

65. Xu Z, Pothula SP, Wilson JS, Apte MV: Pancreatic cancer and its stroma: a conspiracy theory. World J Gastroenterol 2014, 20 $11216-11229$

66. Rhim AD, Oberstein PE, Thomas DH, Mirek ET, Palermo CF, Sastra SA, Dekleva EN, Saunders T, Becerra CP, Tattersall IW, Westphalen CB, Kitajewski J, Fernandez-Barrena MG, FernandezZapico ME, Iacobuzio-Donahue C, Olive KP, Stanger BZ: Stromal elements act to restrain, rather than support, pancreatic ductal adenocarcinoma. Cancer Cell 2014, 25:735-747

67. Moffitt RA, Marayati R, Flate EL, Volmar KE, Loeza SG, Hoadley KA, Rashid NU, Williams LA, Eaton SC, Chung AH, Smyla JK, Anderson JM, Kim HJ, Bentrem DJ, Talamonti MS, Iacobuzio-Donahue CA, Hollingsworth MA, Yeh JJ: Virtual microdissection identifies distinct tumor- and stroma-specific subtypes of pancreatic ductal adenocarcinoma. Nat Genet 2015, 47:1168-1178

68. Stromnes IM, DelGiorno KE, Greenberg PD, Hingorani SR: Stromal reengineering to treat pancreas cancer. Carcinogenesis 2014, 35: $1451-1460$

69. Jang JE, Hajdu CH, Liot C, Miller G, Dustin ML, Bar-Sagi D: Crosstalk between regulatory $\mathrm{T}$ cells and tumor-associated dendritic cells negates anti-tumor immunity in pancreatic cancer. Cell Rep 2017, 20:558-571

70. Ferrone CR, Brennan MF, Gonen M, Coit DG, Fong Y, Chung S, Tang L, Klimstra D, Allen PJ: Pancreatic adenocarcinoma: the actual 5-year survivors. J Gastrointest Surg 2008, 12:701-706 
71. Conlon KC, Klimstra DS, Brennan MF: Long-term survival after curative resection for pancreatic ductal adenocarcinoma: clinicopathologic analysis of 5-year survivors. Ann Surg 1996, 223:273-279

72. van Rijssen LB, Rombouts SJ, Walma MS, Vogel JA, Tol JA, Molenaar IQ, van Eijck CH, Verheij J, van de Vijver MJ, Busch OR, Besselink MG; Dutch Pancreatic Cancer Group: Recent advances in pancreatic cancer surgery of relevance to the practicing pathologist. Surg Pathol Clin 2016, 9:539-545

73. Yu IS, Cheung WY: A contemporary review of the treatment landscape and the role of predictive and prognostic biomarkers in pancreatic adenocarcinoma. Can J Gastroenterol Hepatol 2018, 2018:1863535

74. Le DT, Durham JN, Smith KN, Wang H, Bartlett BR, Aulakh LK, et al: Mismatch repair deficiency predicts response of solid tumors to PD-1 blockade. Science 2017, 357:409-413

75. Adsay VN, Bandyopadhyay S, Basturk O: Duct adjacent to a thickwalled medium-sized muscular vessel in the pancreas is often indicative of invasive adenocarcinoma. Am J Surg Pathol 2006, 30:1203-1205

76. Sharma S, Green KB: The pancreatic duct and its arteriovenous relationship: an underutilized aid in the diagnosis and distinction of pancreatic adenocarcinoma from pancreatic intraepithelial neoplasia: a study of 126 pancreatectomy specimens. Am J Surg Pathol 2004, 28:613-620

77. Bandyopadhyay S, Basturk O, Coban I, Thirabanjasak D, Liang H, Altinel D, Adsay NV: Isolated solitary ducts (naked ducts) in adipose tissue: a specific but underappreciated finding of pancreatic adenocarcinoma and one of the potential reasons of understaging and high recurrence rate. Am J Surg Pathol 2009, 33:425-429

78. Edge SB, Byrd DR, Compton CC, Fritz AG, Greene FL, Trotti A: AJCC Cancer Staging Manual. ed 7. New York, NY: Springer, 2010. pp. $341-350$

79. Hartman DJ, Krasinskas AM: Assessing treatment effect in pancreatic cancer. Arch Pathol Lab Med 2012, 136:100-109
80. Pai RK, Pai RK: Pathologic assessment of gastrointestinal tract and pancreatic carcinoma after neoadjuvant therapy. Mod Pathol 2018, $31: 4-23$

81. Schwarz RE, Smith DD: Extent of lymph node retrieval and pancreatic cancer survival: information from a large US population database. Ann Surg Oncol 2006, 13:1189-1200

82. Tomlinson JS, Jain S, Bentrem DJ, Sekeris EG, Maggard MA, Hines OJ, Reber HA, Ko CY: Accuracy of staging node-negative pancreas cancer: a potential quality measure. Arch Surg 2007, 142: $767-774$

83. Verbeke CS, Menon KV: Redefining resection margin status in pancreatic cancer. HPB (Oxford) 2009, 11:282-289

84. Adsay NV, Basturk O, Saka B, Bagci P, Ozdemir D, Balci S, Sarmiento JM, Kooby DA, Staley C, Maithel SK, Everett R, Cheng JD, Thirabanjasak D, Weaver DW: Whipple made simple for surgical pathologists: orientation, dissection, and sampling of pancreaticoduodenectomy specimens for a more practical and accurate evaluation of pancreatic, distal common bile duct, and ampullary tumors. Am J Surg Pathol 2014, 38:480-493

85. Zhang S, Defrias DV, Alasadi R, Nayar R: Endoscopic ultrasound-guided fine needle aspiration (EUS-FNA): experience of an academic centre in the USA. Cytopathology 2010, 21: $35-43$

86. Lin F, Staerkel G: Cytologic criteria for well differentiated adenocarcinoma of the pancreas in fine-needle aspiration biopsy specimens. Cancer 2003, 99:44-50

87. Felsenstein M, Hruban RH, Wood LD: New developments in the molecular mechanisms of pancreatic tumorigenesis. Adv Anat Pathol 2018, 25:131-142

88. Bettegowda C, Sausen M, Leary RJ, Kinde I, Wang Y, Agrawal N, et al: Detection of circulating tumor DNA in early- and late-stage human malignancies. Sci Trans1 Med 2014, 6:224ra24 